IRA-International Journal of Management \& Social Sciences

ISSN 2455-2267; Vol.03, Issue 03 (2016)

Institute of Research Advances

http://research-advances.org/index.php/RAJMSS

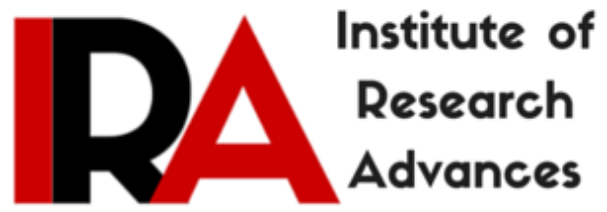

\title{
Trolls and Its Augmentation in the Cyber World of Kerala
}

\author{
Sarada P V \\ Research Scholar \\ St.Aloysius College \\ Elthuruth, Kerala, India.
}

DOI: http://dx.doi.org/10.21013/jmss.v3.n3.p29

\section{How to cite this paper:}

P V, S. (2016). Trolls and Its Augmentation in the Cyber World of Kerala. IRAInternational Journal of Management \& Social Sciences (ISSN 2455-2267), 3(3). doi:http://dx.doi.org/10.21013/jmss.v3.n3.p29

(C) Institute of Research Advances

\section{(cc) EY-NC}

This works is licensed under a Creative Commons Attribution-Non Commercial 4.0 International License subject to proper citation to the publication source of the work.

Disclaimer: The scholarly papers as reviewed and published by the Institute of Research Advances (IRA) are the views and opinions of their respective authors and are not the views or opinions of the IRA. The IRA disclaims of any harm or loss caused due to the published content to any party. 


\begin{abstract}
Internet enthralled new generation cannot think of a world without social media. Social media itself became a platform for open ended discussions and enlightening sources of knowledge. Information revolution creates unbounded world where sumptuous trade, commerce, communication etc take place. The effect of cyber world is far reaching which surmount all other media that facilitates the growth of cyber media. The utility of cyber world is multifaceted.ie it includes entertainment, informative, educative, purposive, etc. Many aspects of internet had far reaching results. Among them trolls are significant in opening the eyes of the audience to the various social, political, gender, lingual and cultural issues. Pointed condemnation, naysayer, satire are the general nature of trolls. Sometimes it focuses on heartless defamation on individuals in power and positions. Ideas that are spread virally through internet may turn out to be reasons for social transformations. It can correct corrupted individuals, modify negative attitude of society towards the underprivileged by poignant criticism through internet trolls. Its interference in social, cultural, political practices is noteworthy to mould a new perspective in society.

Here the endeavor is to find out the concept of trolls and its importance in the cyber world of Kerala. The trolls provide a public space for open criticism and satire. Sometimes it may attack individuals without mercy but generally they are having a wider range of usage. It became instruments of social change when it is used rather in constructive brighter aspects. Sometimes it is used to dismantle the sacred images and idols which are actually beyond the reach of criticism in reality. But the anonymous aspect of virtual world actually opens up a possibility of razor-sharp ridicule and mocking.
\end{abstract}

\title{
Troll
}

Troll is defined as a person who sows discord on the internet by starting arguments or upsetting people by posting inflammatory, extraneous, or off topic messages in an online community with the deliberate intent of provoking readers into an emotional response or of otherwise disrupting normal on topic discussion often for their own amusement. Etymological exploration of the word 'troll' reaches in the early 1980s or before. But the English noun troll in the standard sense of ugly dwarf or giant dates to 1610 and is originated from the Old Norse word 'troll' means giant or demon. Trolls in Scandinavian folklore and children's tales are really antisocial, quarrelsome and slow witted creatures which make annoyance for travelers. Presently the word trolling is used to describe the fishing technique of slowly dragging a lure or baited hook from a moving boat whereas trawling describes the generally commercial act of dragging fishing net. Eventually the contemporary usage of the word appeared on the internet in the late 1980s.

In Chinese, trolling is referred to as bái mù (literally: "white eye"), which can be straightforwardly explained as "eyes without pupils", in the sense that whilst the pupil of the eye is used for vision, the white section of the eye cannot see, and trolling involves blindly talking nonsense over the internet, having total disregard to sensitivities or being oblivious to the situation at hand, akin to having eyes without pupils. An alternative term is bái làn (literally: "white rot"), which describes a post completely nonsensical and full of folly made to upset others. 


\section{Features of Trolls}

The term "troll" can mean a number of different things, but in essence, a troll is a person who aims to have 'pleasure' at your expense. They are people who pretend to be someone that they are not - they create personae that you think are real, but they know is fictitious. Significant attributes of trolls are hilarious, satirizing, correcting, educative, entertaining, uproarious, provocative, offensive and blaming.

\section{Functions of Trolls}

Trolls sometimes act as a modern version of clowns who played a significant role in the genre of drama. They actually tease and exploit human foibles in order to speak the truth. Generally internet trolls hide behind anonymous accounts and fake usernames. They are the tricksters in cyber world and are targeting a nameless audience via the internet.

\section{Types of Trolls}

Corporate trolls:

Nowadays trolls are commonly used to manipulate public opinion. So corporate utilize such aspect of trolls to affect the outlook of the public. Such trolls with a definite implicit intention are called as corporate trolls. Sharyl Attkisson is a media person who recently reports about the increasing trend for organizations to utilize trolls to manipulate public opinion as part and parcel of any company initiative. This trolls are nowadays a strategy and tool of success for most of the business groups.

\section{Political trolls:}

Trolls are created with a motivation of political interests is universal in contemporary society. Politically biased trolls itself is an apparatus of change in the political scenario of many countries. As in the case of Egypt and the Jasmine revolution the interference of cyber world and its impacts are unavoidable. It is true that Chinese government is estimated to produce over 400 million fake social media posts every year, in order to promote pro-government material.

Special interest sponsored trolls:

These are commonly observed trolls used by certain groups with a hidden intention. Sponsored trolls are used to overwhelm any honest discourse upon certain special interest and denigrate any who disagree with them. Such a well organized planning is there behind such trolls.

\section{Four Grades of Trolls}

Playtime Trolls: Here the attack or provocation is fairly blatant and the persona is two dimensional. It is like a simple and short game.

Tactical Trolls: This is more serious kind of trolls. Here deliberately a credible persona is created to gain confidence of others and provokes discords in a subtle and invidious way. 
Strategic Trolls: These are serious trolls which needs months or years to develop. Here strategically a group of people acted together to invade a list.

Domination Trolls: Here the troller's strategy extends to the creation and running of apparently authentic mailing lists.

\section{Personality of Trolls}

Generally trolls are anonymous which provided an opportunity of lending the instincts rather freely on the net. The sadism, antisocial behavior, psychopathic, and Machiavellianism which are suppressed in an individual get an articulation. Collectively all these traits are replicated in the trolls. Trolls are usually done to bullying both adolescents and adults. This sometimes creates merciless amusement, teasing and exploiting the human foibles.

\section{Famous Troll Groups in Kerala}

Earlier Kerala is known as 'the gods own country' but this is the time to rename it as 'Kerala- the trolls own country' .this is the radical changes evident in the cyber space of Kerala. The innumerable troll groups in Malayalam provide ample evidence for the growth of online satire and virtual attacks. The word based SMS gives way to the trolls which includes Words pictures, moving images. And thus begins a new tradition of cyber mocking and satire. Troll Malayalam, International Chalu Union, Arshabaharatha Samskaram, Cyber Trollers etc. are The famous troll groups.

Troll Malayalam

This is one of the most viewed trolls in Malayalam in which trolls are created by modifying cliché scenes and dialogues from popular films. Innovation and divergent thinking is the soul of such trolls which are highly effective. The images given below will certainly provide the explanation.
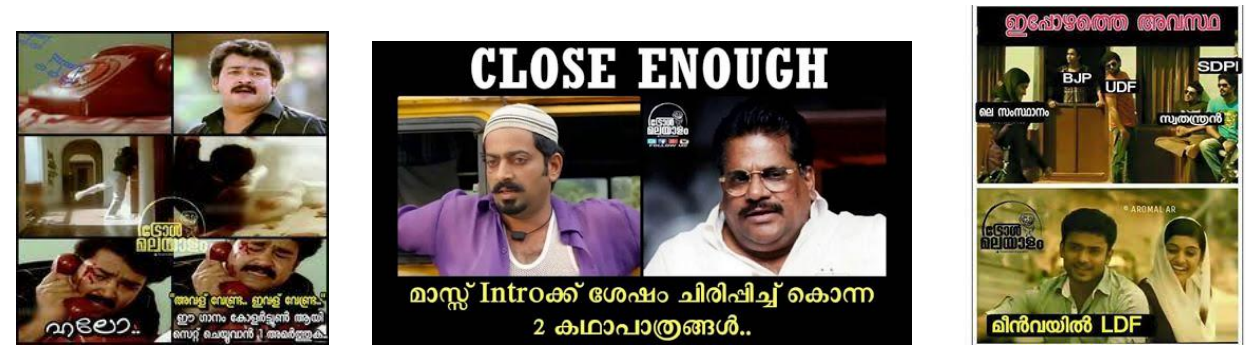

\section{International Chalu Union}

This is the troll group invented by Roshan Thomas to instigate trolls which are devoid of vulgarity, ambiguity, gender disparity, caste discrimination, etc.ICU is now known for its huge number of followers with wider acceptance. Some trolls produced by ICU are given below. 

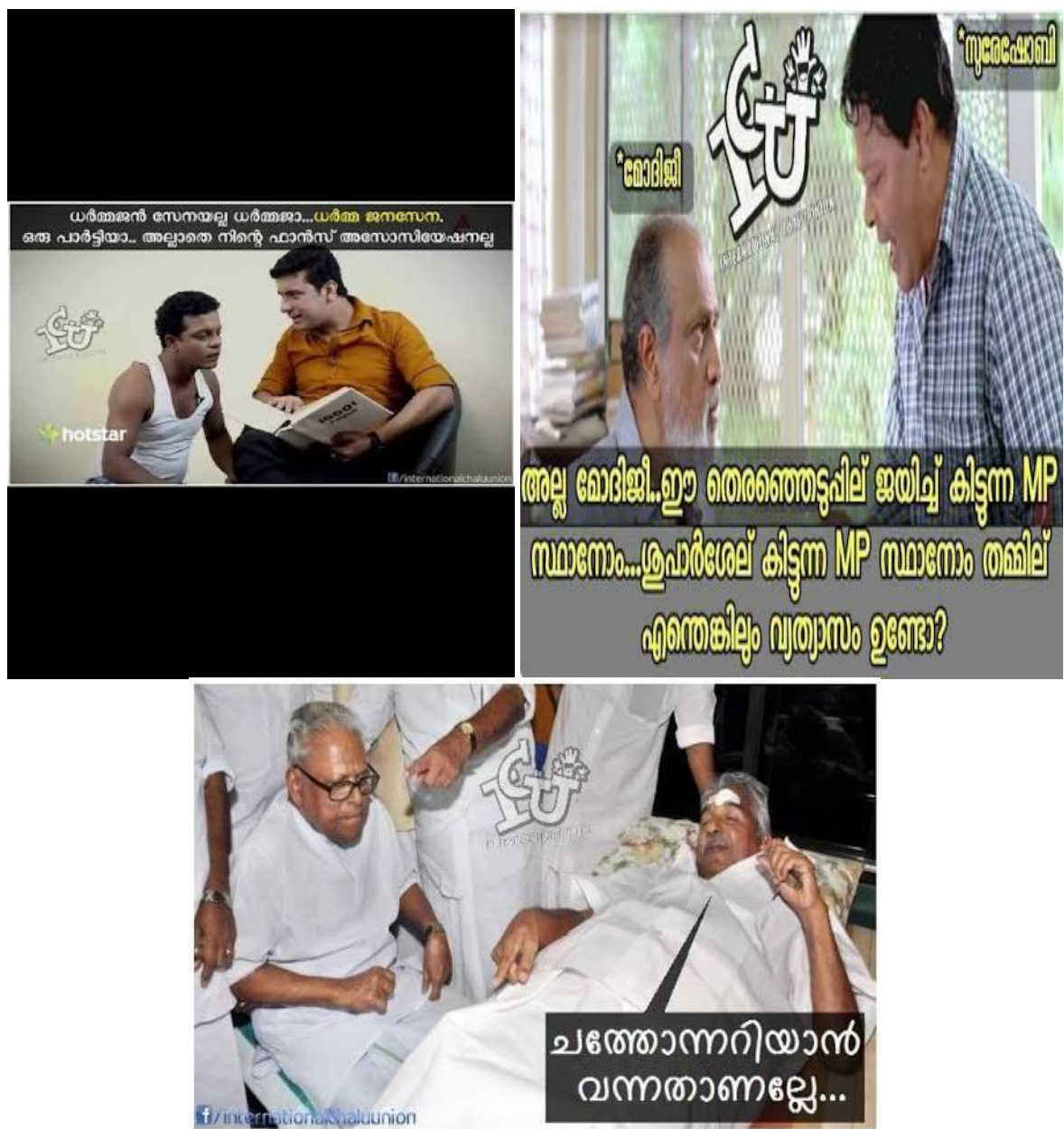

Exuberance of trolls in Malayalam reveals the growing demand of online audience for sharp criticism against all kinds of foibles in society. Changes can be implemented with the use of trolls is evident when we analyze the political scenario of Kerala. Political leaders and the eminent personalities are constantly under the monitoring of the internet trolling. Politically motivated trolls are even having the potential of twisting the public opinions.

\section{Victims of Trolls}

The personality of individuals may be affected by the growing phenomena of trolls. social and psychological suffocation may be the result. But when it is concentrating on general foibles of society it will be enhancing constructive aspect that generates social wellbeing. Victims of trolls are individuals whose position or status may be treated as a point of criticism. Traditional media had a well structured boundary for criticizing politics and its leaders. But the new gadget media does not have strictly limited rules and regulations in the area of satire or ridicule. Thus trolls are treated as a tool of ridicule in the modern cyber world.

Victims of trolls in the contemporary society of Kerala are mostly from politics. Earlier their authority and superiority is beyond doubts but nowadays all aspects 
are under the focus of observation. But many believed that the best way to tackle the issue of trolls is to ignore it. But on the whole the relevance of trolls is increasing in a world of information revolution as a tool to protest in a way of ridiculing, mocking and sometimes provoking.

\section{Bibliography}

Bishop, Jonathan (2013). The effect of de-individuation of the Internet Troller on Criminal .An Interview with a Hater (PDF). International Journal Of

\section{Cyber Criminalology}

www.netlingo.com/word/troll.php

https://en.wikipedia.org/wiki/Internet_troll

https://darkpsychology.co

https://www.researchgate.net

https://www.scribd.com

https://www,theguardian.com

https://www.psychologytoday.com

https://buzzfeed.com

https://www.smosh.com

webtrends.about.com 